\title{
Consumer Attitude Regarding Food Labelling and Perception of Healthier Choice Logo (HCL)
}

\author{
Fatimah $S^{1,3 *}$, Ruhaya $S^{2}$ and Zainudin $M A^{3}$ \\ ${ }^{1}$ Nutrition Division, Ministry of Health Malaysia \\ ${ }^{2}$ Institute of Public Health, Ministry of Health Malaysia \\ ${ }^{3}$ Negeri Sembilan State Health Department, Ministry of Health Malaysia \\ *Corresponding author: Fatimah S, Negeri Sembilan State Health Department, Ministry of Health Malaysia, Nutrition Division, \\ Malaysia
}

ARTICLE INFO

Received: 幽 March 29, 2019

Published: 幽 April 12, 2019

Citation: Fatimah S, Ruhaya S, Zainudin MA. Consumer Attitude Regarding Food Labelling and Perception of Healthier Choice Logo (HCL). Biomed J Sci \& Tech Res 17(1)-2019. BJSTR. MS.ID.002936.

Keywords: Label; Nutrition Labelling; Front-of-Pack; Healthier Choice; Health Symbol

\begin{abstract}
The study was conducted to determine the consumer attitude regarding food labelling and perception of HCL in Malaysia. A total of 366 consumers aged between 18 and 60 years in Negeri Sembilan participated in the study. An interviews or guided self-administered survey was conducted using a convenient sampling method. The results showed that about $60 \%(n=221)$ of the respondents agreed that nutrition information on food label could affect their food intake, influence a buying decision $(72 \%, \mathrm{n}=265)$ and help them in choosing healthier products $(79 \%, n=288)$. Majority of the respondents $(80 \%, n=294)$ supported the implementation of HCL. About $81 \%(n=297)$ of the respondents believed that the use of the HCL on the logo is foreseen to increase one's confidence in choosing food products. Even though this initiative may incur the price, $60 \%(n=220)$ of them would still choose to buy the products that bears the HCL. The most trustworthiness authority other than government for the HCL was the professional bodies $(70 \%, \mathrm{n}=255)$. There is a possibility that such logo system could encourage food manufacturers to reformulate existing products or develop new products to improve their nutritional compositions. Therefore, it is important to explore further the possibility beneficial impact of FOP labelling systems to the producers and retailers who implement them.
\end{abstract}

Abbreviations: NCDs: Non-Communicable Diseases; BOP: Back-of-Package; FOP: Frontof-Package; CCFL: Codex Committee on Food Labelling; HCL: Healthier Choice Logo; MTL: Multiple Traffic Lights; GDA: Guideline Daily Amounts; WHO: World Health Organization; NPANM: National Plan of Action for Nutrition Malaysian; WHA: World Health Assembly; MREC: MOH Research and Ethics Committee; NMRR: National Medical Research Register; SPSS : Statistical Package for Social Sciences; HCL : Healthier Choice Logo; NIP : Nutrition Information Panel; HPB : Health Promotion Board; NHMS : National Health and Morbidity Survey; MDG : Malaysian Dietary Guidelines; NIP: Nutrition Information Panel; NHF : National Heart Foundation; CSPI: Center for Science in the Public Interest

\section{Introduction}

Food labelling is one of the means of communication between the producer and seller of food on one hand, and the purchaser and consumer on the other FAO/WHO, [1]. Many governments are adopting such policy which has been identified as an important tool in response to increasing incidence of obesity and chronic non-communicable diseases (NCDs) WHO, [2]). Generally, nutrition label falls into two categories, the back-of-package (BOP) and the front-of-package (FOP) labels Mandle et al. [3]. BOP nutrition label informs consumers of nutritional properties of a food. It is a listing of the level of nutrients as declared as a table in one section of a food label, commonly known as a nutrition information panel or NIP FSQD [4]. FOP nutrition label is an addition to the currently mandated NIP. During the Forty-Fourth Session of Codex Committee on Food Labelling (CCFL) in 2017, FOP systems were classified as interpretive and informative systems. Interpretive systems (or summary indicator or criteria-based systems) include symbols, icons, colour codes and graphic representations such as Healthier Choice Logo (HCL), Multiple Traffic Lights (MTL) or 
health star rating. Informative systems (nutrient- specific systems) may include the Guideline Daily Amounts (GDA) or energy icon. In this system, the nutrition information from the NIP is stated in a more concise way without any interpretation. However, there is no international guidelines on implementation of FOP system. While the World Health Organization (WHO) is still developing guidance for countries considering FOP labelling systems, and manufacturers continued to develop variety of FOP systems, concerns were raised about what a variety of systems might mean to consumers.

The availability of various FOP systems could also create problems for export and trade and can lead to technical barriers to trade FAO/WHO, [5]. FOP labelling has also been a prominent issue in Asian Region. Thailand has announced mandatory GDA labels for five snack categories as pioneers in 2011 before expansion to other categories Rimpeekool et al. [6]. EUFIC [7] reported that Singapore and Thailand have implemented the Healthier Choice Symbol, while Philippines has opted for "Wise Eat" logo. In 2017, Healthier Choice Logo was also launched in Brunei. In line with the strategy of the National Plan of Action for Nutrition Malaysian (NPANM) III (2016-2025) and the 65th World Health Assembly (WHA) 2012 resolution to promote healthy eating, Healthier Choices Logo (HCL) was launched by the Ministry of Health Malaysia on 20th April 2017 Nutrition Division [8]. This initiative is part of the strategy to assist consumers in adopting healthy dietary practices by making wise food choices at the point of purchase, as well as to encourage food industries to produce healthier food options to be available in the market Nutrition Division [8]. National study to review the proposal of using certain symbol or logo such as "healthier choice" was carried out by Task Force Committee on Healthier Choice under Ministry of Health in 2008. However, the findings of the study of 1936 respondents from 15 states were not published elsewhere.

Recognizing the importance of this issue, this study can provide evidence to national stakeholders and policymaker on the consumer's response towards the labelling system. Therefore, the present study aimed to determine the consumer attitude regarding food labelling and perception of HCL in Malaysia. It is hoped that information gathered will be able to help relevant authorities to strengthen consumer understanding of nutrition information displayed on food labels.

\section{Materials and Methods}

\section{Subjects}

A total of 366 respondents aged 18-60 years old were recruited using a convenient sampling method during state health activities in Negeri Sembilan. In this survey, female respondents constituted $71 \%(n=260)$ of the sample study compared to male, $29.0 \%$ $(n=106)$. Majority were Malays (84\%), followed by 7\% Chinese, 6\% Indians and $3 \%$ other races (such as Kadazan, Bajau and Murut). About $27 \%$ of the respondents were in the 18-24 years of age group, $25-34$ years $(15 \%), 35-44$ years $(29 \%), 45-54$ years $(19 \%)$ and $55-$ 60 years (10\%). Almost half (48\%) had achieved secondary level of education and proportions completed primary school, diploma/ certificate, degree holders were $2 \%, 34 \%$ and $16 \%$ respectively. However, such specific procedure in recruiting the subject to avoid biasness as well as to represent the Malaysian population structure, particularly in Negeri Sembilan, cannot be implemented due to poor cooperation from the public as well as limitation of numerator.

\section{Survey Instrument}

The questionnaire was designed to be administered by interview on a one-to-one basis or guided self-administered. To establish the content validity, nine (9) experts in the areas of food labelling, nutrition labelling and signposting were asked to review the questionnaire. Each reviewer independently rated the relevance of each section in the questionnaire using a 4-point likert scale (1=not relevant, $2=$ quite relevant, $3=$ relevant, $4=$ very relevant). The questionnaire was piloted in 24 subjects from the community and improved for intended purpose and usefulness. The average time taken to finish the questionnaire was about 20 minutes. Cronbach's alpha was measured to examine the internal consistency of the questionnaire. Items that gave an alpha of at least 0.70 was acceptable for survey instrument used in the study. The questionnaire consisted of a few main sections. These sections included demography information, attitude towards food labelling and perception of Healthier Choice Logo (HCL). Section on demography information collected data on general characteristics of the respondents including gender, race, age and education level. Attitude towards food labelling and perception of HCL were assessed using a 5-point likert scale. Only statements that meet certain Cronbach's alpha $(\bigotimes)$ value were used in the study.

\section{Ethical Approval}

An appropriate ethical approval was obtained from the $\mathrm{MOH}$ Research and Ethics Committee (MREC) (NMRR-16-1252-31661) and institutional and registered at National Medical Research Register (NMRR) prior to implementing the study. All the information from the questionnaire was kept confidential. Any data containing respondents' personal information will not be disclosed to protect the information privacy and confidentiality.

\section{Data Analysis}

The data collected was analysed using Statistical Package for Social Sciences (SPSS) version 16.0. Descriptive and analytic analysis were done accordingly.

\section{Results}

\section{Attitude towards Food Labelling}

Attitude towards food labelling was assessed using a 5-point likert scale. Those who answered "1" and " 2 " were categorized as "not agree", " 3 " as "not sure", while "4" and "5" as "agree". The findings related to the attitude towards food labelling were presented in Table 1 . About $60 \%$ of the respondents agreed that nutrition information on FOP can affect their food intake, gives truthful nutrition information and nutritional content on FOP was easily understood, $51 \%$ and $26 \%$ respectively. Related to choices of products that could be affected by food label, respondents agreed that FOP can change a buying decision, help them to compare products when making choices and choosing healthier products (72\%, 78\% and 79\% respectively). Figure 1 showed the nutrition information that the respondents read on food label when buying food products. The mean for expiry date was found the highest 
(4.37 \pm 0.70 ), followed by ingredient, "good" nutrient and nutrition lower means were nutrition information panel, "bad" nutrient and claims $(4.10 \pm 0.74,3.99 \pm 0.79$ and $3.91 \pm 0.77$ respectively). The $\quad$ food additives $(3.85 \pm 0.84,3.87 \pm 0.82$ and $3.87 \pm 0.84$ respectively)

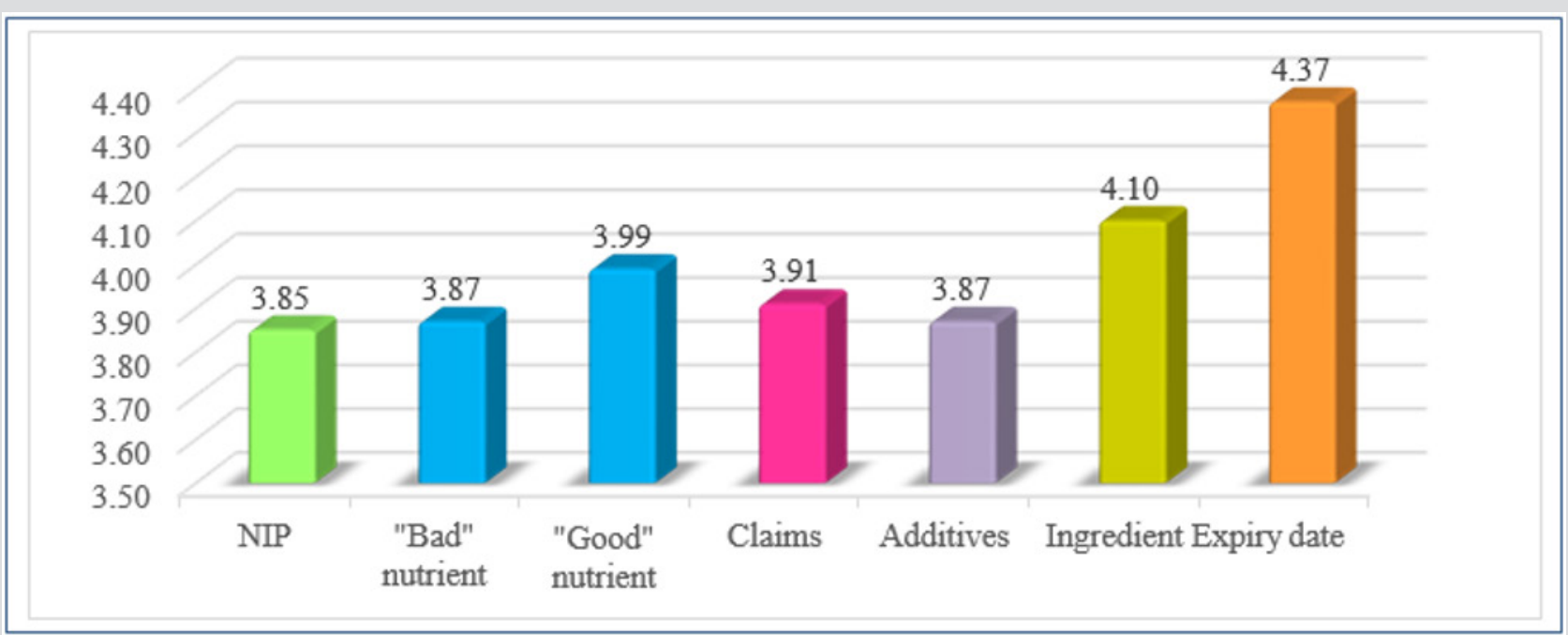

Figure 1: Information read on food label when buying food products.

Table 1: Attitude towards food label.

\begin{tabular}{|c|c|c|c|c|c|c|c|c|c|}
\hline \multirow[t]{3}{*}{ Scope } & \multirow[t]{2}{*}{ Statement } & \multicolumn{6}{|c|}{ Number of respondent, $\mathbf{n}$ and percentage } & \multirow{3}{*}{$\begin{array}{l}\text { Mean } \\
3.73\end{array}$} & \multirow{3}{*}{$\begin{array}{l}\text { S.D. } \\
0.96\end{array}$} \\
\hline & & \multicolumn{2}{|c|}{ "Not agree" } & \multicolumn{2}{|c|}{ "Not sure" } & \multicolumn{2}{|c|}{ "Agree” } & & \\
\hline & $\begin{array}{l}\text { 1) Nutrition info on FOP } \\
\text { affects food intake. }\end{array}$ & 46 & $(12.6)$ & 99 & $(27.0)$ & 221 & $(60.4)$ & & \\
\hline \multirow[t]{2}{*}{ Content } & $\begin{array}{l}\text { 2) FOP gives truthful } \\
\text { nutrition information. }\end{array}$ & 20 & $(5.5)$ & 159 & $(43.4)$ & 187 & $(51.1)$ & 3.88 & 0.83 \\
\hline & $\begin{array}{l}\text { 3) Nutrition info on FOP is } \\
\text { easily understood. }\end{array}$ & 50 & $(13.7)$ & 96 & $(26.2)$ & 220 & $(60.1)$ & 3.99 & 0.87 \\
\hline \multirow{3}{*}{$\begin{array}{l}\text { Product } \\
\text { choices }\end{array}$} & $\begin{array}{l}\text { 1) FOP can change a buying } \\
\text { decision. }\end{array}$ & 48 & $(13.1)$ & 53 & $(14.5)$ & 265 & $(72.4)$ & 3.73 & 0.96 \\
\hline & $\begin{array}{l}\text { 2) Nutrition info can help in } \\
\text { product comparison. }\end{array}$ & 24 & $(6.5)$ & 58 & $(15.8)$ & 284 & $(77.6)$ & 3.88 & 0.83 \\
\hline & $\begin{array}{l}\text { 3) FOP can help in choosing } \\
\text { healthier products. }\end{array}$ & 19 & $(5.2)$ & 59 & (16.1) & 288 & (78.7) & 3.99 & 0.87 \\
\hline
\end{tabular}

\section{Perception of Healthier Choice Logo (HCL)}

During this study, HCL initiative was not yet implement in Malaysia. Respondents' perception towards the Healthier Choice Logo (HCL) on food label was assessed using a 5-point likert scale. Those who answered " 1 " and " 2 " were categorized as "not agree", " 3 " as "not sure", while " 4 " and " 5 " as "agree". Table 2 showed that about $80 \%(n=294)$ of the respondent supported the Table 2: Perception towards Healthier Choice Logo (HCL). implementation of HCL and agreed that the use of the HCL would increase one's confidence in choosing food products (81\%, $n=297)$. In this study, $60 \%(n=220)$ of the respondents choose to buy the products that had the logo even if this initiative may cause price increase on the food products. Even though the product may carry HCL logo, 60\% ( $\mathrm{n}=218)$ would still refer to nutrition information panel (NIP) on the label.

\begin{tabular}{|c|c|c|c|c|c|c|c|c|c|}
\hline \multirow[t]{2}{*}{ Scope } & Statement & \multicolumn{6}{|c|}{ Number of respondents, $n$ and percentage } & \multirow{3}{*}{$\begin{array}{c}\text { Mean } \\
4.05 \\
\end{array}$} & \multirow{3}{*}{$\begin{array}{l}\text { S.D. } \\
0.78 \\
\end{array}$} \\
\hline & & \multicolumn{2}{|c|}{ “Not agree" } & \multicolumn{2}{|c|}{ "Not sure" } & \multicolumn{2}{|c|}{ “Agree" } & & \\
\hline \multirow{4}{*}{$\begin{array}{c}\text { The logo } \\
\text { (HCL) }\end{array}$} & 1) Support the HCL implementation & 10 & $(2.7)$ & 62 & $(16.9)$ & 294 & $(80.3)$ & & \\
\hline & $\begin{array}{l}\text { 2) Hcl gives confident to choose the product } \\
\text { with this logo. }\end{array}$ & 9 & $(2.5)$ & 60 & $(16.4)$ & 297 & $(81.1)$ & 4.08 & 0.76 \\
\hline & $\begin{array}{l}\text { 3) Will choose the product with hcl even at } \\
\text { higher price. }\end{array}$ & 37 & $(10.1)$ & 109 & $(29.8)$ & 220 & $(60.1)$ & 3.66 & 0.99 \\
\hline & $\begin{array}{l}\text { 4) Will still refer to nip even though the label } \\
\text { has hcl. }\end{array}$ & 26 & $(7.1)$ & 122 & $(33.3)$ & 218 & $(59.6)$ & 3.70 & 0.89 \\
\hline
\end{tabular}




\begin{tabular}{|c|c|c|c|c|c|c|c|c|c|}
\hline \multirow{3}{*}{$\begin{array}{c}\text { Preference } \\
\text { authority } \\
\text { (Other than } \\
\text { MOH) }\end{array}$} & 1) Food industry & 59 & $(16.1)$ & 70 & $(19.1)$ & 237 & $(64.8)$ & 3.58 & 1.07 \\
\hline & 2) Consumer association & 38 & $(10.4)$ & 89 & $(24.3)$ & 239 & $(65.3)$ & 3.70 & 0.98 \\
\hline & 3) Professional bodies & 32 & $(8.7)$ & 79 & $(21.6)$ & 255 & (69.7) & 3.81 & 0.97 \\
\hline
\end{tabular}

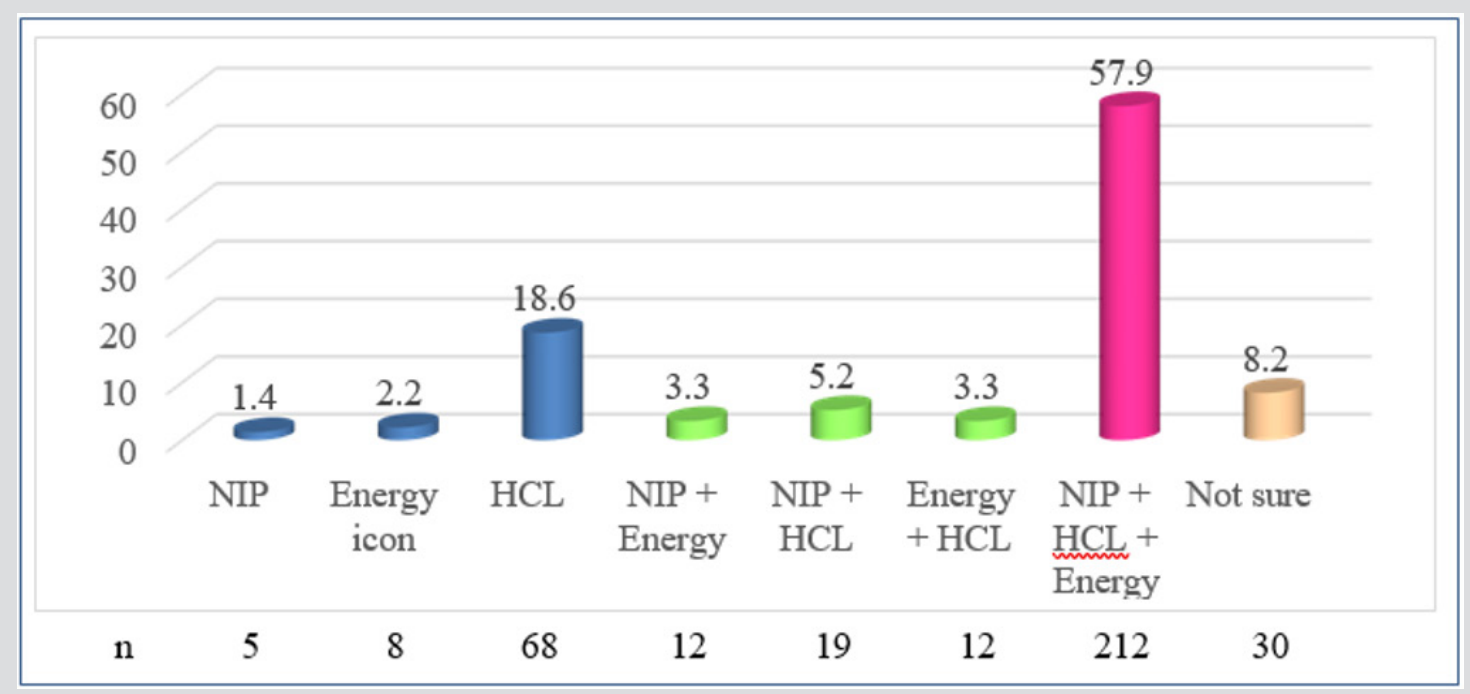

Figure 2: Possible initiatives to help in choosing food products.

Table 2 also showed the authority preferred by the respondents to certify products to be given HCL. Other than Ministry of Health, $70 \%(n=255)$ preferred professional bodies to be the authority to certify HCL products. Other bodies that could become the certification authorities were consumer association and food manufacturer, 65.3\% $(n=239)$ and $64.8 \%(n=237)$ respectively.

The possible initiatives preferred by the respondents to help them in choosing food products were presented in Figure 2. It was clear that combination of three labelling systems consisted of nutrition information panel (NIP), Healthier Choice Logo (HCL) and energy icon was most preferred by the respondents $(57.9 \%$, $\mathrm{n}=212)$. The least preferred was declaration NIP alone, 1.4\% $(n=5)$.

\section{Discussion}

\section{Attitude towards Food Labelling}

Generally, various studies from a wide range of countries on nutrition labelling showed evidence that nutrition labelling is a useful tool that provides nutrient information for consumer to make informed food choices Hawkes et al. [9-12]. Nutrition label was also reported to have impact on diets especially among those who read the label Hawkes [9]; Coulson [13]. A study in Thailand also showed that about $52 \%$ of consumers identified healthier food products by using the information from the GDA labels Rimpeekool et al. [6]. Based on unpublished data from the Singapore Health Promotion Board (HPB) in 2004, 69\% of consumers had used Healthier Choice Symbol to assist them in making healthier food options Soon et al. [14].

Consistent with those findings, this study has shown that FOP can change a buying decision and help them in comparing products when making healthier products choices. Other studies related to general use of nutrition labelling in Malaysia reported that, about $87 \%$ of consumers in Kelantan looked for nutrition label while purchasing food products. They believed that food products which had nutrition information on food label was quality products Zul Arif \& Mohamad Amizi, [15]. Norazlanshah et al. [16] found a significant association between attitude and the use of nutrition labelling on food purchasing decision among 165 respondents in Kuantan. Another study in Selangor showed that $58 \%$ of the respondents were "often" and "sometimes" used of nutrition information on food label during buying food product Nurliyana, Norazmir \& Khairil Anuar [17].

In line with National Health and Morbidity Survey (NHMS) findings in 2014, present study also found that expiry date was the most popular information the respondents read on food label when buying food products. A study on the understanding of the Malaysian Dietary Guidelines (MDG) in 2010 showed that more than half of the respondents were not aware on the health messages in the MDG IPH [18]. Unfamiliarity to the technical terms and negligence of certain nutrient information that they perceived as not important to their health also contributed to the low prevalence of reading food label IPH [18].

\section{Perception of Healthier Choice Logo (HCL)}

During this study, HCL was not yet implement in Malaysia. However, a series of technical discussion about HCL was done as early as 2006. Hence, there was no education about HCL labelling system from Ministry of Health during this study. Some of the respondents were aware of the similar system based on their experience in other countries. A review study of the Pick The Tick logo used in Australia and New Zealand reported that education of FOP system may take some years before consumer can understand the meaning of the logo Mhurchu \& Gorton [19]. Another similar programme is the Choices programme which was introduced in the Netherland in 2006. Through communication campaigns that was implemented during the first year after the logo was introduced, more than $80 \%$ of the Netherland population was familiar with the logo compared to $30 \%$ at the beginning Vyth et al. [20]. 
The results of the present study indicated that majority of the respondents (80\%) supported the implementation of HCL for it may help them in making food choices. These findings were parallel with the study conducted in Europe by Feunekes et al. [21] where it was found that Healthier Choice Tick may be more effective in helping consumers to choose food products. A review study by Hawley et al. [22] also indicated that such logo did not promote an increased consumption of 'less unhealthy' products that qualified for the logo. Even though there was no further research on the public health impact pertaining to the logo, environment with healthier options for various type of food products may help to improve population dietary intake.

The HCL was expected to have some impact on purchasing behaviour. Research conducted within the Netherlands on the actual use of Choices logo showed that more consumers consciously buying products bearing the logo compared to those who indicated not consciously buying products with the logo Vyth et al. [23]. Approximately, $60 \%$ of the respondents from this study indicated that they would choose to buy the food products even they were sold at higher price. Thomson et al. [24] reported that the Tick programme in New Zealand had encouraged food manufacturers to reformulate and produce healthier products. The Center for Science in the Public Interest (CSPI) also reported that a major Swedish retailer, inköpscentralernas aktiebolag (ICA) had used the keyhole symbol on food labels. The sales of food products bearing the symbol rose over 15\% between 2003 and 2004 CSPI [25].

There may be a possibility that such symbol or logo system could encourage food manufacturers to reformulate existing products or develop new products to improve their nutritional compositions. According to the food product reformulation records kept by National Heart Foundation (NHF) from 1 July 1998 to 30 June 1999, many Tick products had either been invented or reformulated to meet the Tick requirements, particularly nutrient criteria for fat and sodium Young \& Swinburn [26]. However, to our best of knowledge, there is no study in Malaysia examines the possibility beneficial impact of FOP labelling system to the producers and retailers who implement them. Therefore, it is important to explore further in FOP nutrition labels in the context of Malaysian population.

The findings of this study showed that the most trustworthiness authority other than government was the professional bodies. A professional body is usually a nonprofit organization whose members are individuals engaged in that profession and the public interest. Some studies reported that consumers' trust in nutrition information on food labels would be higher if they trusted the information sources Vyth et al. [20]; Grunert \& Wills [27]. A study in Europe found that $71 \%$ trusted the information sources for nutrition information came from a third party compared to selfcertified schemes EAHC [28]. These findings indicated that such logo system when been developed by the industry, it was usually perceived to be less trustworthy.

The findings of this study concluded that the consumers preferred the nutrition information panel (NIP) been declared together with the FOP symbols. This is an indication of how a FOP labelling such as HCL and energy icon can attract food label reading habits alongside NIP labelling. Another study found that simpler FOP symbols were more effective in helping consumers to identify healthier products Feunekes et al. [21]. IOM [29] reported that research on FOP symbol systems is limited and there were no label systems that developed on FOP alone. FOP is to be used in conjunction with the nutrition labelling. Food industries developed FOP label systems to provide consumers with summaries of the nutritional properties of the product to guide them in making healthier choices Kunkel \& McKinley [30]. This study had shown that although there would be HCL logo, $60 \%$ of the respondents were expected to still refer to NIP at the back-of-pack (BOP) of the food label. Another study conducted by Reid et al. [31] had shown that the overall use of nutrition information on food label was related to Health Check Logo in Canada.

\section{Conclusion}

In conclusion, providing appropriate food and nutrition information to the public becomes of prime importance in the battle against diet-related chronic diseases. This study found that FOP was expected to have some impact on consumers' buying decision and may help them in making food choices. However, this study also did not deal with the role of FOP in guiding consumers at the point of purchasing decisions in real-life settings. Future study is recommended to clarify further a possibility beneficial impact that such logo system could encourage food manufacturers to reformulate existing products or develop new products to improve their nutritional compositions.

\section{Acknowledgement}

We would like to extend our grateful thanks to the Director General of Health, Malaysia for the opportunity to publish this study. This work was supported by the Negeri Sembilan State Health Department. We thank the respective nutritionists in Negeri Sembilan, especially Mr Mohamad Ihsan Tahir and Ms Farah Wahida Za'abar for assistance rendered.

\section{References}

1. (2007) FAO/WHO Food Labelling Fifth Edition. Joint FAO/WHO Food Standards Programme, Rome.

2. (2013) WHO Global action plan for the prevention and control of noncommunicable diseases 2013-2020. Geneva.

3. Mandle J, Tugendhaft A, Michalow J, Hofman K (2015) Nutrition labelling: A review of research on consumer and industry response in the global south. Global Health Action.

4. (2010) Food Safety and Quality Division (FSQD). Guide to nutrition labelling and claims as at December 2010. Ministry of Health Malaysia, Putrajaya.

5. (2017) FAO/WHO Discussion paper on consideration of issues regarding front-of-pack nutrition labelling. Codex Committee on Food Labelling. Joint FAO/WHO Food Standards Programme, Rome.

6. Rimpeekool W, Banwell C, Seubsman S, Kirk M, Yiengprugsawan V, et al. (2016) I rarely read the label: Factors that influence Thai consumer responses to nutrition labels. Global Journal of Health Science 8(1): 2128.

7. (2017) European Food Information Council (EUFIC). Global Update on Nutrition Labelling.

8. (2017) Nutrition Division. Guidelines on Healthier Choice Logo Malaysia. Ministry of Health Malaysia, Putrajaya.

9. Hawkes C (2004) Nutrition labels and health claims: The global regulatory environment. World Health Organization, Geneva. 
10. Kim SY, Nayga RM, Capps O (2000) The effect of food label use on nutrient intakes: An endogenous switching regression analysis. Journal of Agricultural and Resource Economics 25(1): 215-231.

11. Abbott R (1997) Food and nutrition information: A study of sources, uses, and understanding. British Food Journal 99(2): 43-49.

12. Shine A, O Reilly S, O Sullivan K (1997) Consumer use of nutrition labels. British Food Journal 99(8): 290-296

13. Coulson NS (2000) An application of the stages of change model to consumer use of food labels. British Food Journal 102(9): 661-668.

14. Soon G, Koh YH, Wong ML, Lam PW (2008) Obesity prevention and control efforts in Singapore. The National Bureau of Asian Research (NBR), USA.

15. Zul Ariff AL, Mohamad Amizi A (2015) Food nutrition impact toward rural consumer in Kelantan. Australian Journal of Basic and Applied Sciences 9(24): 40-43.

16. Norazlanshah H, Muhammad I, Hasmira Md, Mashita M, Norfazilah Mr, et al. (2013) The use of nutrition label on food purchasing decision among university students in Kuantan, Malaysia. Health and the Environment Journal 4(1): 1-10.

17. Nurliyana G, Norazmir MN, Khairil Anuar MI (2011) Knowledge, attitude and practices of university students regarding the use of nutritional information and food labels. Asian Journal of Clinical Nutrition 3(3): 7991.

18. (2014) Institute for Public Health (IPH). National Health and Morbidity Survey 2014: Malaysian Adult Nutrition Survey (MANS) Vol. II: Survey Findings.

19. Mhurchu CN, Gorton D (2007) Nutrition labels and claims in New Zealand and Australia: A review of use and understanding. Australian and New Zealand Journal of Public Health 31(2): 105-112.

20. Vyth EL, Steenhuis IHM, Mallant SF, Mol ZL, Brug J, et al. (2009) A frontof-pack nutrition logo: A quantitative and qualitative process evaluation in the Netherlands. Journal of Health Communication 14(7): 631-645.

\section{ISSN: 2574-1241}

DOI: 10.26717/BJSTR.2019.17.002936

Fatimah S. Biomed J Sci \& Tech Res

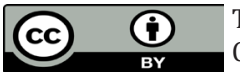

This work is licensed under Creative Commons Attribution 4.0 License

Submission Link: https://biomedres.us/submit-manuscript.php
21. Feunekes GIJ, Gortemaker IA, Willems AA, Lion R, Van den Kommer M (2008) Front-of-pack nutrition labelling: Testing effectiveness of different nutrition labelling formats front-of-pack in four European countries. Appetite 50(1): 57-70.

22. Hawley KL, Roberto CA, Bragg MA, Liu PJ, Schwartz MB, et al. (2013) The science on front-of-package food labels. Public Health Nutrition 16(3): 430-439.

23. Vyth EL, Steenhuis IHM, Vlot JA, Wulp A, Hogenes MG, et al. (2010) Actual use of a front-of-pack nutrition logo in the supermarket: Consumers' motives in food choice. Public Health Nutrition 13(11): 1882-1889.

24. Thomson RK, McLean RM, Ning SX, Mainvil LA (2016) Tick front-of-pack label has a positive nutritional impact on foods sold in New Zealand. Public Health Nutrition 19(16): 2949-2958.

25. (2006) Center for Science in the Public Interest (CSPI). Petition for advance notice of proposed rulemaking on the use of symbols on the principal display panel to communicate the healthfulness of foods.

26. Young L, Swinburn B (2002) Impact of the Pick the Tick food information programme on the salt content of food in New Zealand. Health Promotion International 17(1): 13-19.

27. Grunert K, Wills J (2007) A review of European research on consumer response to nutrition information on food labels. Journal of Public Health 15(5): 384-399.

28. (2013) Executive Agency for Health and Consumers (EAHC). Consumer market study on the functioning of voluntary food labelling schemes for consumers in the European Union - Final report.

29. (2012) Institute of Medicine (IOM). Front-of-package nutrition rating systems and symbols: Promoting healthier choices, DC: The National Academies Press Washington USA.

30. Kunkel D, McKinley C (2007) Developing ratings for food products: Lessons learned from media rating systems. Journal of Nutrition Education and Behaviour 39(2 Supplement): S25-S31.

31. Reid RD, Slovinec D Angelo ME, Dombrow CA, Heshka JT, Dean TR (2004) The heart and stroke foundation of Canada's Health Check food information program: Modelling program effects on consumer behaviour and dietary practices. Canadian Journal of Public Health 95(2): 146-150.

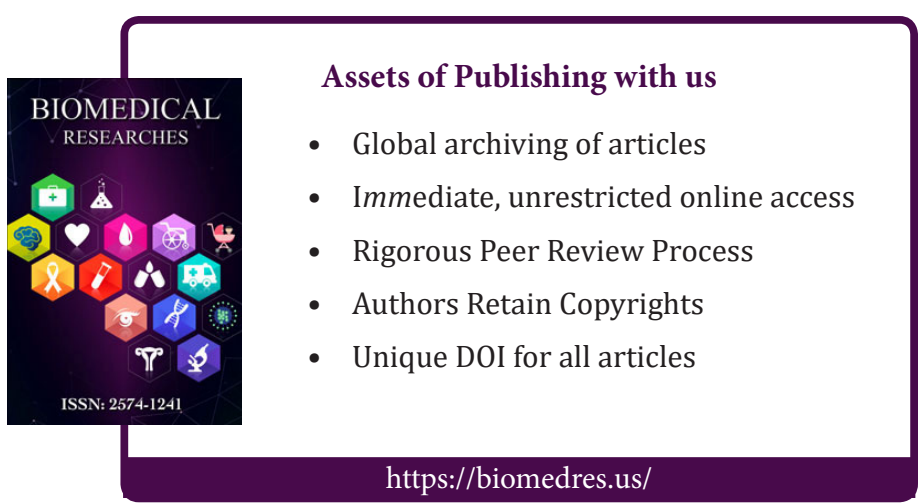

